Article

\title{
Encapsulation of Co single sites in covalent triazine frameworks for photocatalytic production of syngas
}

\author{
Yajun He, Xin Chen, Chi Huang, Liuyi Li *, Chengkai Yang, Yan Yu\# \\ Key Laboratory of Eco-materials Advanced Technology, College of Materials Science and Engineering, Fuzhou University, Fuzhou 350108, Fujian, China
}

\section{A R T I C L E I N F}

\section{Article history:}

Received 26 February 2020

Accepted 10 April 2020

Published 5 January 2021

\section{Keywords:}

Photocatalysis

Covalent triazine frameworks

$\mathrm{CO}_{2}$ reduction

Single site

Syngas

\begin{abstract}
A B S T R A C T
The photocatalytic production of syngas using a noble-metal-free catalytic system is a promising approach for renewable energy and environmental sustainability. In this study, we demonstrate an efficient catalytic system formed by integrating Co single sites, which act as the active sites, in covalent triazine frameworks (CTFs), which act as the photoabsorber, for the photocatalytic production of syngas from $\mathrm{CO}_{2}$ in aqueous solution. The enhanced light absorption of the CTFs, which contain intramolecular heterojunctions, in conjunction with $0.8 \mathrm{mmol} \mathrm{L}^{-1}$ of the Co complex enables excellent syngas production with a yield of $3303 \mu \mathrm{mol} \mathrm{g}^{-1}\left(\mathrm{CO}: \mathrm{H}_{2}=1.4: 1\right)$ in $10 \mathrm{~h}$, which is about three times greater than that achieved using CTF without a heterojunction. In the photocatalytic reaction, the coordinated single Co centers accept the photogenerated electrons from the CTF, and serve as active sites for $\mathrm{CO}_{2}$ conversion through an adsorption-activation-reaction mechanism. Theoretical calculations further reveal that the intramolecular heterojunctions highly promote photogenerated charge separation, thus boosting photocatalytic syngas production. This work reveals the promising potential of CTFs for single-metal-site-based photocatalysis.
\end{abstract}

(C) 2021, Dalian Institute of Chemical Physics, Chinese Academy of Sciences. Published by Elsevier B.V. All rights reserved.

\section{Introduction}

Syngas (a mixture of $\mathrm{CO}$ and $\mathrm{H}_{2}$ ) is a key precursor for the production of bulk chemicals by Fischer-Tropsch processing $[1,2]$. Currently, syngas is mainly prepared by the reforming of natural gas or coal gasification, which requires harsh synthesis conditions $[3,4]$. The simultaneous photocatalytic reduction of $\mathrm{CO}_{2}$ and $\mathrm{H}_{2}$ evolution from water is one of the sustainable strategies for the production of syngas for chemical production [5]. So far, many photocatalytic systems have been developed for the production of syngas [6-10]. However, most of these systems use expensive metals such as Re and Ru as photosensi- tizers and/or catalysts with high efficiency [11]. Thus, developing efficient catalytic systems utilizing earth-abundant but highly active metal catalysts for photocatalytic syngas production is highly desirable, but remains challenging [12].

Molecular-metal-complex-based photocatalytic systems have shown promising catalytic performance in the photoreduction of $\mathrm{CO}_{2}$ [13]. The coordinated metal centers serve as single active sites in the catalytic reaction $[14,15]$. Their coordinative versatility endows metal active sites with tailorable electronic properties [16-19], which are favorable for optimization of the catalytic efficiency. However, most of these systems suffer from insufficient stability and separation of the

\footnotetext{
* Corresponding author. E-mail: lyli@fzu.edu.cn

\# Corresponding author. E-mail: yuyan@fzu.edu.cn

This work was supported by the National Natural Science Foundation of China (U1905215, 51672046), Natural Science Foundation of Fujian Province of China (2019J01226), and Open Project Program of the State Key Laboratory of Photocatalysis on Energy and Environment (SKLPEE-KF201815).

DOI: 10.1016/S1872-2067(20)63603-8 | http://www.sciencedirect.com/science/journal/18722067 | Chin. J. Catal., Vol. 42, No. 1, January 2021
} 
expensive metal catalysts. Thus, the heterogenization of metal complexes that convert $\mathrm{CO}_{2}$ in a semiconductor may combine their high catalytic activity with the classic advantages of heterogeneous catalysis [20-23]. To maximize the atom utilization efficiency, the selection of a semiconductor with the porosity to accommodate metal single sites is required [24]. Additionally, to readily control the catalytic activity, a semiconductor possessing a tunable energy band structure is also needed.

Covalent triazine frameworks (CTFs) have recently emerged as a new class of photoactive materials due to their tunable light-harvesting properties and adjustable electronic structures at the molecular level [25-29]. Their high surface area and nitrogen-rich structure endow CTFs with distinct advantages for the accommodation of guest molecules [30] and very importantly, the guest molecules are accessible to the reactants in catalysis [31-33]. In spite of their merits, there have been only a few reports of the use of CTFs in the field of photocatalytic production of syngas so far [34]. Herein, we demonstrate the utilization of CTFs for the production of syngas via the photoreduction of $\mathrm{CO}_{2}$ in aqueous solution. CTFs containing triphenylamine and triazine units as intramolecular heterojunctions are employed for the accommodation of molecular Co complexes, which serve as active single sites for $\mathrm{CO}_{2}$ conversion. The resultant catalytic system exhibits excellent photocatalytic performance, which is ascribed to the efficient transfer of the photogenerated carriers due to the intramolecular heterojunctions in the CTFs and the well-stabilized single Co active sites in the framework.

\section{Experimental}

\subsection{Synthesis of CTFs}

The CTFs prepared from 1,4-benzene-dialdehyde and

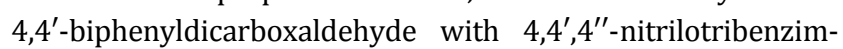
idamide trihydrochloride are referred to as CTF-TPN and CTF-TDPN, respectively.

Synthesis of CTF-TPN. A mixture of $4,4^{\prime}, 4^{\prime \prime}$-nitrilotribenzimidamide trihydrochloride (336 $\mathrm{mg}, 0.69 \mathrm{mmol})$, 1,4-phthalaldehyde $(69.9 \mathrm{mg}, 0.52 \mathrm{mmol})$, and cesium carbonate $(752.6 \mathrm{mg}, 2.31 \mathrm{mmol})$ in DMSO $(5.5 \mathrm{~mL})$ and $\mathrm{H}_{2} \mathrm{O}(0.2$ $\mathrm{mL}$ ) was heated at $60^{\circ} \mathrm{C}, 80^{\circ} \mathrm{C}$, and $100^{\circ} \mathrm{C}$ for $12 \mathrm{~h}$ respectively, and at $120{ }^{\circ} \mathrm{C}$ for $72 \mathrm{~h}$. The resulting product was filtered and washed three times with water, acetone, and tetrahydrofuran individually, and then dried at $60{ }^{\circ} \mathrm{C}$ for $12 \mathrm{~h}$ under vacuum to yield CTF-TPN as a yellow powder.

Synthesis of CTF-TDPN. Following the same procedures as in the synthesis of CTF-TPN, CTF-TDPN was obtained by the polycondensation of $4,4^{\prime}, 4^{\prime \prime}$-nitrilotribenzimidamide trihydrochloride and 4,4'-biphenyldicarboxaldehyde as a yellow powder.

\subsection{Characterization}

All the starting materials were used without further purification. The FTIR spectra of the as-synthesized CTFs were recorded with a Nicolet 5700 instrument. The ${ }^{1} \mathrm{H}$ and ${ }^{13} \mathrm{C}$ NMR spectra were recorded on a Bruker AVANCE III NMR. High performance liquid phase chromatography (HPLC) was performed on an Agilent 1260 Infinity II. Powder X-ray diffraction (PXRD) patterns were obtained in the range of $2 \theta=3^{\circ}-40^{\circ}$ on a DY5261/Xpert3 diffractometer with $\mathrm{Cu} K_{\alpha}$ radiation $(\lambda=$ $1.5406 \AA$ A). Thermogravimetric analysis (TGA) was carried out on a NETZSCH STA 449C instrument over the temperature range $30^{\circ}-800{ }^{\circ} \mathrm{C}$ under a nitrogen atmosphere with a heating rate of $10{ }^{\circ} \mathrm{C} \mathrm{min}-1$. X-ray photoelectron spectrometry (XPS) was performed on a Thermo ESCALAB 250 spectrometer using nonmonochromatic $\mathrm{Al} K_{\alpha} \mathrm{X}$-rays as the excitation source and choosing C $1 s$ (284.6 eV) as the reference line. Nitrogen adsorption and desorption isotherms were measured at $77 \mathrm{~K}$ using an ASAP 2460 system. The samples were degassed at $80^{\circ} \mathrm{C}$ for 12 $\mathrm{h}$ before the measurements. The surface areas were calculated from the adsorption data using the Brunauer-Emmett-Teller (BET) equation. Solid-state UV-vis diffuse reflectance spectra (UV-vis DRS) were recorded at room temperature with a UV-vis spectrophotometer (Agilent Cary 5000 spectrometer) using powder samples. Field-emission scanning electron microscopy (SEM) was performed on a JEOL JSM-7500F operated at an accelerating voltage of $3.0 \mathrm{kV}$. Transmission electron microscopy (TEM) images were obtained with a TECNAI G2 F20. The photoluminescence (PL) spectra were obtained using an Edinburgh FL/FS900 spectrophotometer with an excitation wavelength at $365 \mathrm{~nm}$. Time-resolved fluorescence emission decay spectra were recorded with a FLS1000. The content of Co was analyzed by inductively coupled plasma optical emission spectrometry (ICP-OES; iCAP 7000, Thermo Fisher Scientific Inc.). Gas chromatographic analysis (GC) was conducted using an Agilent Technologies-7890B instrument equipped with a flame ionization detector (FID), a thermal conductivity detector (TCD), and a TD-01 packed column. The CO gas produced in the ${ }^{13} \mathrm{CO}_{2}$ isotope experiments was analyzed using a gas chromatograph-mass spectrometer (GC-MS, Agilent 7890B-5977B).

\subsection{Photocatalytic $\mathrm{CO}_{2}$ reduction performance}

The photocatalytic reactions were performed in a Schlenk flask containing cobalt(II) acetate tetrahydrate $\left(0.8 \mathrm{mmol} \mathrm{L}^{-1}\right)$, 2,2'-bipyridine (15.6 mg, $0.1 \mathrm{mmol})$, and CTF (10 mg) in $5 \mathrm{~mL}$ of an acetonitrile/triethanolamine $/ \mathrm{H}_{2} \mathrm{O}(v / v / v=3: 1: 1)$ solution. The Schlenk flask was purged with $\mathrm{CO}_{2}$ gas three times and charged with $\mathrm{CO}_{2}$ (1.0 bar) for 10 min until the solution reached $\mathrm{CO}_{2}$ saturation. The mixture was then irradiated under a Xe lamp (300 W) with a $\lambda \geq 420 \mathrm{~nm}$ cutoff filter. After the reaction, the gases were analyzed by GC. The recycling experiments were carried out for $2 \mathrm{~h}$ under visible light irradiation $(\lambda$ $\geq 420 \mathrm{~nm}$ ) as described above. CTF was recovered by centrifugation and washed with acetonitrile $(10 \mathrm{~mL} \times 3)$ after the reaction was completed. The recovered CTF was then reused in the subsequent cycle experiment with fresh 2,2'-bipyridine and Co salt. The apparent quantum yield (AQY) at $420 \mathrm{~nm}$ was calculated using the following equation: $\mathrm{AQY}=[(2 \times$ amount of $\mathrm{CO}$ and $\mathrm{H}_{2}$ molecules evolved in $2 \mathrm{~h}$ )/(number of incident photons in $2 \mathrm{~h}$ )] $\times 100 \%$. The single Co sites were formed in-situ by the coordination of 2,2'-bipyridine and Co ions, and were encapsu- 
lated within the CTFs in the photocatalytic reaction.

\subsection{Theoretical calculations}

The DFT calculation utilized the B3LYP hybrid functional basis sets. The DMOL3 program was employed. All molecules were optimized using the DNP basis set. The maximum tolerances for force and atom displacements along any Cartesian component were $0.002 \mathrm{Ha} \AA^{-1}$ and $5 \times 10^{-3} \AA$, respectively, and the SCF tolerance was $1 \times 10^{-6}$. The final morphology was determined from the model when the lowest total energy was reached.

\section{Results and discussion}

\subsection{Structure characterization}

CTF-TPN and CTF-TDPN were synthesized by reacting 4,4',4"-nitrilotribenzimidamide trihydrochloride with either 1,4-phthalaldehyde or 4,4'-biphenyldicarboxaldehyde, respectively (Fig. 1). The Fourier transform infrared spectra (FT-IR) of the CTFs show the typical peaks for the triazine ring at 1508 and $1370 \mathrm{~cm}^{-1}$ (Fig. 2a), revealing the success of the trimerization reactions [35]. The characteristic signal at $170 \mathrm{ppm}$ in the solid state ${ }^{13} \mathrm{C}$ NMR spectrum was attributed to the carbon atoms in the triazine rings (Fig. 2b). The additional signals at $149.1,138.1$, and 128.9 ppm were assigned to the carbon atoms in the aromatic rings. The X-ray photoelectron spectroscopy (XPS) survey scan showed that the elements $\mathrm{C}, \mathrm{N}$, and $\mathrm{O}$ coexisted in CTF-TPN and CTF-TDPN (Fig. S1). The N $1 s$ peak can be resolved into two peaks. The peak at $398.6 \mathrm{eV}$ was ascribed to the $\mathrm{N}$ atom of the triazine moieties, and the other

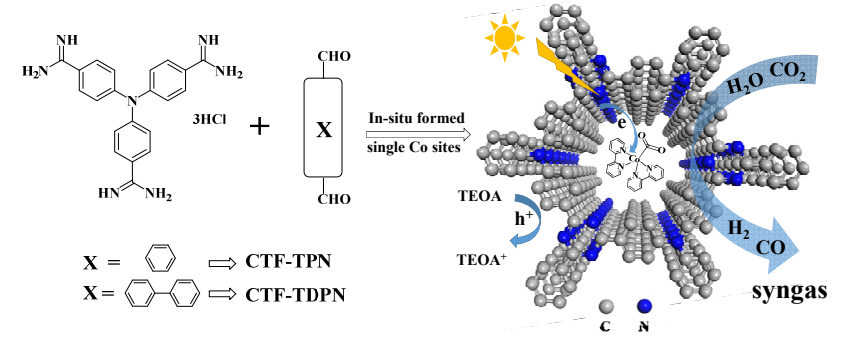

Fig. 1. Schematic of the synthesis of CTF-TPN and CTF-TDPN and their application in the photocatalytic reduction of $\mathrm{CO}_{2}$ under visible light.

peak at $399.9 \mathrm{eV}$ corresponds to the $\mathrm{N}$ atom in the triphenylamine moiety (Fig. 2c) [36,37], further verifying the coexistence of triphenylamine and triazine moieties in the frameworks. The PXRD patterns show that CTF-TPN and CTF-TDPN were amorphous (Fig. 2d), mainly owing to the fast nucleation rates [38].

The porosities of CTF-TPN and CTF-TDPN were investigated using $\mathrm{N}_{2}$ adsorption-desorption experiments at $77 \mathrm{~K}$ (Fig. 3a). The initial $\mathrm{N}_{2}$ uptake in CTF-TPN and CTF-TDPN demonstrated the existence of micropores. The Brunauer-Emmett-Teller (BET) surface areas of CTF-TPN and CTF-TDPN were $206 \mathrm{~m}^{2}$ $\mathrm{g}^{-1}$ and $310 \mathrm{~m}^{2} \mathrm{~g}^{-1}$, respectively. Interestingly, appreciable amounts of $\mathrm{CO}_{2}$ adsorption were also observed. The $\mathrm{CO}_{2}$ uptakes of CTF-TPN and CTF-TDPN at $273 \mathrm{~K}$ and $1 \mathrm{~atm}$ were 64 $\mathrm{mg} \mathrm{g}^{-1}$ and $40 \mathrm{mg} \mathrm{g}^{-1}$ (Fig. 3b and S2), which may be attributed to their nitrogen-rich microporous structures. The isosteric heat of adsorption $\left(Q_{\mathrm{st}}\right)$ values of CTF-TPN and CTF-TDPN for $\mathrm{CO}_{2}$ sorption at zero coverage were $31.74 \mathrm{~kJ} \mathrm{~mol}^{-1}$ and $33.48 \mathrm{~kJ}$ $\mathrm{mol}^{-1}$ (inset in Fig. 3b), respectively, confirming their affinity for $\mathrm{CO}_{2}$. Scanning electron microscopy (SEM) images show that CTF-TPN and CTF-TDPN were composed of granular particles
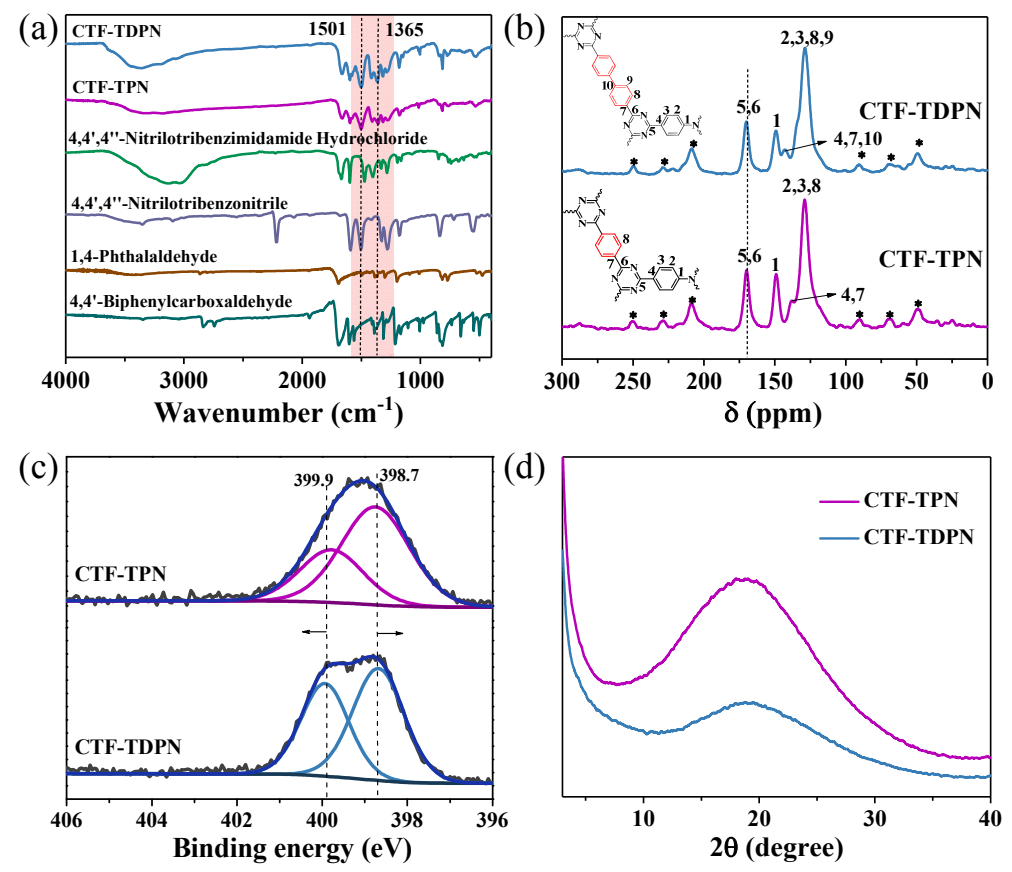

Fig. 2. (a) FTIR spectra of the monomers and CTFs; (b) Solid state ${ }^{13} \mathrm{C}$ NMR spectra, (c) N $1 s$ XPS profiles, and (d) XRD patterns of CTF-TPN and CTF-TDPN. 

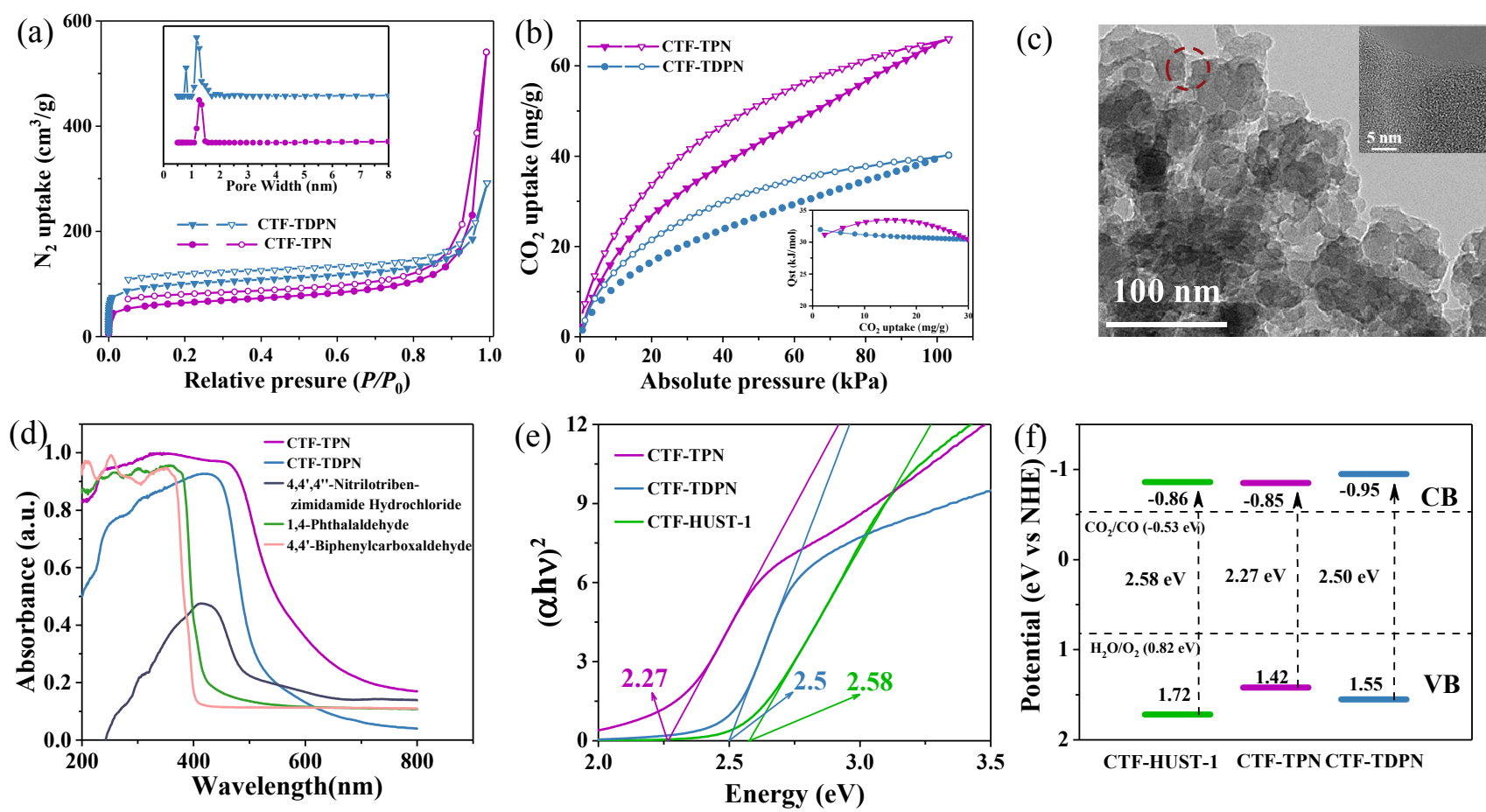

Fig. 3. (a) $\mathrm{N}_{2}$ adsorption-desorption isotherms at $77 \mathrm{~K}$ (inset: pore size distribution); (b) $\mathrm{CO}_{2}$ adsorption-desorption isotherms at $273 \mathrm{~K}$ (inset: isotherms of the heat of adsorption for $\mathrm{CO}_{2}$ ) of CTF-TPN and CTF-TDPN; (c) TEM image of CTF-TDPN; (d) UV-vis DRS spectra; (e) band gaps of the CTFs; (f) band structures of the CTFs.

(Fig. S3). The high-resolution transmission electron microscopy (HR-TEM) images indicate that the particles consisted of stacked nanosheets (Fig. 3c). Thermal gravimetric analysis (TGA) measurements of CTF-TPN and CTF-TDPN show their high thermal stability, with stability up to $350^{\circ} \mathrm{C}$ (Fig. S4). The slight mass loss below $200^{\circ} \mathrm{C}$ can be attributed to the residual solvent or organic oligomers in the pores of the CTFs.

The optical properties of CTF-TPN and CTF-TDPN were further characterized. The UV-visible diffuse-reflectance spectra (UV-Vis DRS) show that CTF-TPN and CTF-TDPN could strongly harvest visible light over a wide range (Fig. 3d). The red shift of their absorption edges in comparison to the monomers was attributed to the increased $\pi$-electron delocalization in the conjugated framework [39]. For comparison, CTF-HUST-1, which lacks triphenylamine moieties, was synthesized [40], as shown in the experimental section of the supporting information. CTF-TPN and CTF-TDPN displayed broader absorption edges and narrower band gaps than CTF-HUST-1, showing the that introduction of triphenylamine units into the framework efficiently enhanced visible light harvesting [41]. The energy band structures obtained from the UV-Vis DRS (Fig. 3e) and Mott-Schottky analyses (Fig. S5) reveal that the reduction potentials of CTF-TPN and CTF-TDPN energetically favored $\mathrm{CO}_{2}$ reduction (Fig. 3f), making them attractive for the photocatalytic reduction of $\mathrm{CO}_{2}$.

\subsection{Photocatalytic activity}

In light of their suitable band structure and $\mathrm{CO}_{2}$ adsorption capacity, the photocatalytic performances of CTF-TPN and
CTF-TDPN for $\mathrm{CO}_{2}$ reduction were evaluated using the in situ formed $\left[\mathrm{Co}(\text { bpy) } 3]^{2+}\right.$ (bpy = 2,2'-bipyridine) as a cocatalyst and triethanolamine (TEOA) as an electron donor. Under the optimized reaction conditions, the kinetic profiles show that CO and $\mathrm{H}_{2}$ evolved simultaneously under visible light irradiation and increased with reaction time (Fig. $4 \mathrm{a}$ and $4 \mathrm{~b}$ ). The gas production of CTF-TPN and CTF-TDPN reached $3368 \mu \mathrm{mol} \mathrm{g}^{-1}$ and $3303 \mu \mathrm{mol} \mathrm{g}{ }^{-1}\left(\mathrm{CO}: \mathrm{H}_{2}=1.4: 1\right)$ in $10 \mathrm{~h}$ of irradiation, respectively. The apparent quantum yield (AQY) of $\mathrm{CO}$ and $\mathrm{H}_{2}$ evolution at $420 \mathrm{~nm}$ was calculated to be $0.14 \%$. For comparison, CTF-HUST-1 was employed in the reaction under identical conditions and showed much lower activity than CTF-TPN and CTF-TDPN (Fig. 4c and S6), suggesting the importance of the triphenylamine units in the framework for the photocatalytic reduction of $\mathrm{CO}_{2}$ to $\mathrm{CO}$.

Control experiments showed no activity in the absence of $\mathrm{Co}^{2+}$ or 2,2'-bipyridine, while a considerable amount of $\mathrm{CO}$ and $\mathrm{H}_{2}$ was detected in the presence of $\left[\mathrm{Co}(\text { bpy) }]_{3}\right]^{2+}$ (Fig. $\left.4 \mathrm{~d}\right)$, which proved that the activity resulted from the in situ formed $\left[\mathrm{Co}(\mathrm{bpy})_{3}\right]^{2+}$. An isotope experiment was carried out using ${ }^{13} \mathrm{CO}_{2}$ as the carbon source to confirm the source of the produced CO. As shown in Fig. S7, the peaks at $m / z=29$ and $m / z=$ 13 confirmed that the source of the produced $\mathrm{CO}$ was ${ }^{13} \mathrm{CO}_{2}$ gas rather than other organic species in the photocatalytic system. No by-products of $\mathrm{CO}_{2}$ reduction such as $\mathrm{CH}_{4}, \mathrm{CH}_{3} \mathrm{OH}$, or HCOOH were detected in solution NMR spectrum (Fig. S8) or HPLC spectrum (Fig. S9). The yield of CO matched well with the UV-vis DRS spectrum of CTF-TDPN (Fig. S10). As the amount of CTF in the reaction was increased from 1 to $10 \mathrm{mg}$, the production of syngas increased (Fig. S11), proving that the photocata- 



Fig. 4. Photocatalytic evolution of $\mathrm{CO}$ and $\mathrm{H}_{2}$ by (a) CTF-TPN and (b) CTF-TDPN; (c) comparison of the average CO and $\mathrm{H}_{2}$ evolution efficiencies of the CTFs; (d) control experiments using CTF-TDPN; (e) experiments using different solvents; (f) experiments with different $\mathrm{H}_{2} \mathrm{O}$ contents in the reaction. MeCN, DMF, DMC, and Diox are acetonitrile, $N, N$-dimethylformamide, $N, N$-dimethylacetamide, and 1,4-dioxane, respectively.

lytic reduction of $\mathrm{CO}_{2}$ to $\mathrm{CO}$ was indeed induced by light irradiation of the CTFs. Increasing the concentration of $\left[\mathrm{Co}(\mathrm{bpy})_{3}\right]^{2+}$ in the reaction led to an increase in $\mathrm{H}_{2}$ production with a slight decrease in $\mathrm{CO}$ production (Fig. S12). When the concentration of $\left[\mathrm{Co}(\mathrm{bpy})_{3}\right]^{2+}$ was increased to $0.8 \mathrm{mmol} \mathrm{L}-1$, a $\mathrm{CO} / \mathrm{H}_{2}$ ratio of approximately 1:1 was obtained. The activity of CTF-TDPN in different organic solvents was correlated with its fluorescence intensity in the corresponding solvent (Fig. 4e). The content of $\mathrm{H}_{2} \mathrm{O}$ in the reaction played an important role in the composition of the produced syngas (Fig. 4f). Only a small amount of $\mathrm{CO}$ was produced in the absence of $\mathrm{H}_{2} \mathrm{O}$. When the volume content of $\mathrm{H}_{2} \mathrm{O}$ was increased from $2.5 \%$ to $20 \%$, the ratio of $\mathrm{CO} / \mathrm{H}_{2}$ decreased from 2.4:1 to 1:1. Above all, the composition of the photocatalytic products could be changed facilely by adjusting the reaction conditions. The reusability of CTF-TDPN for photocatalytic syngas production was studied. After each reaction, the photocatalyst was separated, washed with acetonitrile, and then added to the next reaction. A slight loss of activity for CO and $\mathrm{H}_{2} \mathrm{O}$ production was observed after four cycles (Fig. S13). The FTIR spectrum of the recovered CTFs showed that the typ-
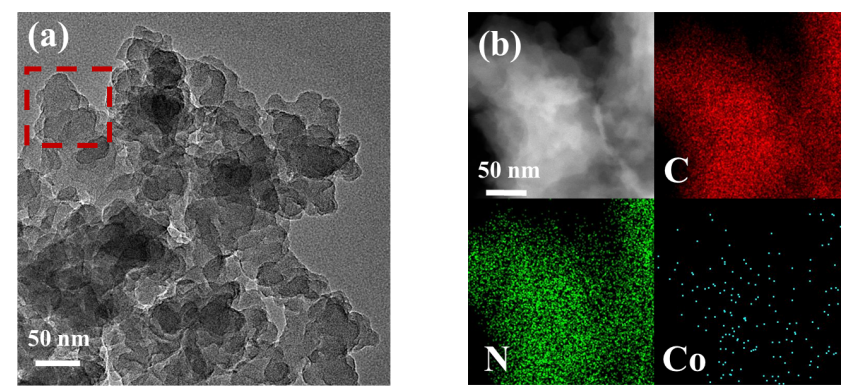

Fig. 5. (a) TEM image and (b) EDX mapping of the recovered CTF-TDPN. ical peaks of the triazine ring at 1508 and $1370 \mathrm{~cm}^{-1}$ were retained in the chemical structure (Fig. S14). Inductively coupled plasma mass spectrometry (ICP) shows that only $0.85 \mathrm{wt} \%$ of Co was present in the recovered CTF-TDPN. The TEM image of recovered CTF-TDPN shows a remain of the nanosheet morphology (Fig. 5a), but no Co-related nanoparticles were observed. EDX elemental mapping shows only weak Co signals on the recovered CTF-TDPN, suggesting weak interaction between the CTF and Co single sites (Fig. 5b). The recovered CTF-TDPN did not generate syngas products in a subsequent reaction in the absence of the Co complex, further suggesting that the interactions between Co active sites and CTF were almost physical.

\subsection{Photocatalytic mechanism}

To investigate the photocatalytic mechanism of the as-prepared CTFs, the photoluminescence (PL) spectra of the CFTs were investigated. Upon excitation at $365 \mathrm{~nm}, \mathrm{CTF}-\mathrm{TPN}$, CTF-TDPN and CTF-HUST-1 emit with maximum emission wavelengths at 553, 538, and $538 \mathrm{~nm}$ in solid state, respectively (Fig. 6a). The emission intensities of CTF-TPN and CTF-TDPN were much stronger than that of CTF-HUST-1, suggesting that the introduction of triphenylamine moieties could promote electron generation, but could also lead to quick recombination of the electron-hole pairs. The time-resolved fluorescence emission decay spectra for the CTFs were obtained and are shown in Fig. 6b. The decay kinetics for CTF-HUST-1, CTF-TPN, and CTF-TDPN show that their respective average fluorescence lifetimes were 2.11, 2.95, and 3.47 ns. The longer fluorescence lifetimes of CTF-TPN and CTF-TDPN compared to that of 

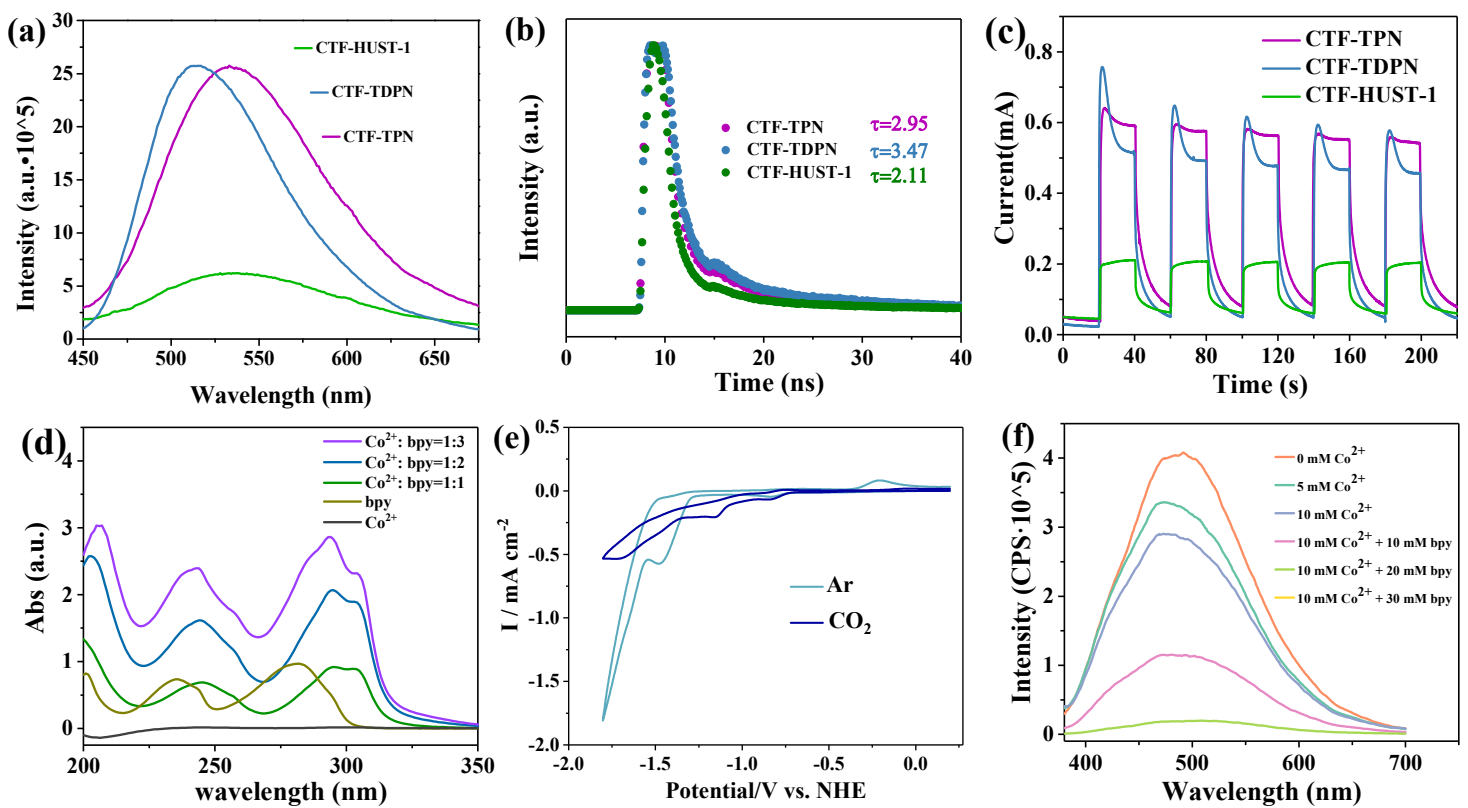

Fig. 6. (a) PL spectra under $365 \mathrm{~nm}$ excitation at room temperature (Inset: CTFs under $365 \mathrm{~nm}$ UV-light); (b) time-resolved fluorescence emission decay spectra; (c) transient photocurrents under visible light ( $\geq 420 \mathrm{~nm}$ ) irradiation of CTF-TPN, CTF-TDPN, and CTF-HUST-1; (d) UV-vis absorption spectra of $\left[\mathrm{Co}(\text { bpy })_{3}\right]^{2+}$ formed in situ by the consecutive addition of bpy to $\mathrm{Co}(\mathrm{OAc})_{2} \cdot 4 \mathrm{H}_{2} \mathrm{O}$ in $\mathrm{MeCN} / \mathrm{H}_{2} \mathrm{O}(v / v=3: 1)$; (e) CV curves of the self-assembled [Co(bpy) $\left.)_{3}\right]^{2+}$ under $\mathrm{Ar}$ and $\mathrm{CO}_{2}$ atmospheres; (f) PL spectra of CTF-TDPN with $\left[\mathrm{Co}(\mathrm{bpy})_{3}\right]^{2+}$ in $\mathrm{MeCN} / \mathrm{H}_{2} \mathrm{O}$ upon irradiation at $365 \mathrm{~nm}$.

CTF-HUST-1 indicate the long lifetime of the photogenerated charge carriers in CTF-TPN and CTF-TDPN, further confirming that the presence of intramolecular heterojunctions could effectively facilitate the separation of photogenerated electrons and holes [42]. Photoelectrochemical measurements of the CTFs revealed that CTF-TPN and CTF-TDPN presented much higher photocurrent densities than CTF-HUST-1 (Fig. 6c). The electrochemical impedance spectroscopy (EIS) Nyquist plot shows smaller charge-transfer resistances in CTF-TPN and CTF-TDPN than in CTF-HUST-1 (Fig. S15). The above results evidenced that the intramolecular heterostructures were beneficial for the generation and separation of charge carriers $[43,44]$.

The role of the Co complex in the photocatalytic $\mathrm{CO}_{2}$ reduction process was also investigated. The UV-vis absorption spectra demonstrate the easy formation of the $\left[\mathrm{Co}(\mathrm{bpy})_{3}\right]^{2+}$ complex upon the addition of the bpy ligand and Co(II) salt to an aqueous solution. The remarkable red-shift of bpy in the UV-vis absorption spectra indicates the coordination of bpy to Co ions (Fig. 6d). Cyclic voltammetry (CV) analysis of the in-situ formed $\left[\mathrm{Co}(\mathrm{bpy})_{3}\right]^{2+}$ aqueous solution shows two primary reduction peaks at -0.83 and $-1.45 \mathrm{~V}$ vs. NHE under an Ar atmosphere (Fig. 6e), which were assigned to the reduction of $\mathrm{Co}^{\mathrm{II}}$ to $\mathrm{Co}^{\mathrm{I}}$ and $\mathrm{Co}^{\mathrm{I}}$ to $\mathrm{Co}^{0}$, respectively [45]. The catalytic current emerged after the $\mathrm{Co}^{\mathrm{II}}$ to $\mathrm{Co}^{\mathrm{I}}$ reduction wave under a $\mathrm{CO}_{2}$ atmosphere, suggesting the reaction of $\mathrm{Co}^{\mathrm{I}}$ with $\mathrm{CO}_{2}$ in the electrochemical process [15]. Moreover, the fluorescence of CTF-TDPN in solution can be significantly quenched by the in-situ formed $\left[\mathrm{Co}(\mathrm{bpy})_{3}\right]^{2+}$ (Fig. 6f), indicating that the active Co single sites originated from the in-situ formed $\left[\mathrm{Co}(\mathrm{bpy})_{3}\right]^{2+}$, which could accept photogenerated electrons from the CTF.

Density functional theory (DFT) calculations of the optimized structures of the building blocks were further performed to study the electronic details of the CTFs. For CTF-TPN, the HOMO was located on the triphenylamine unit, while the LUMO was distributed on the triazine ring (Fig. 7a). These orbital locations are conducive to the separation of photogenerated

(a)
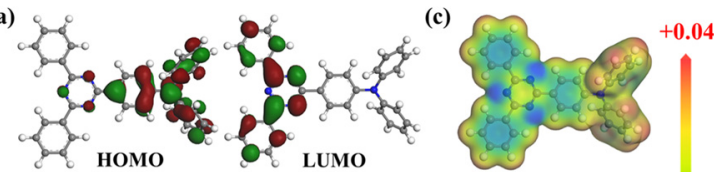

(b)

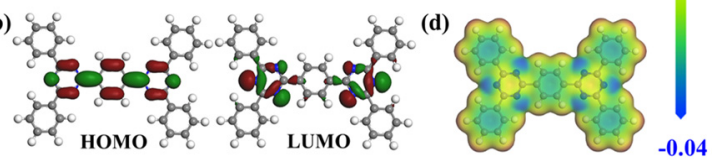

(e)

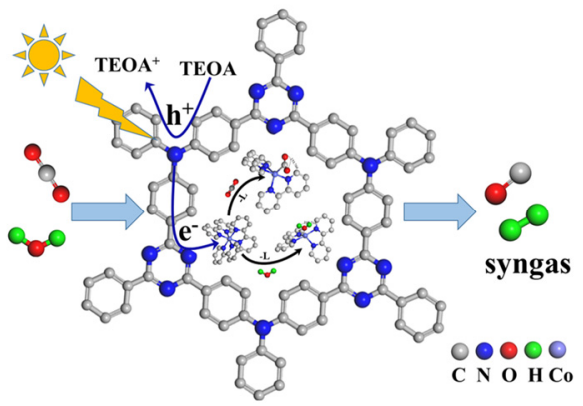

Fig. 7. HOMOs and LUMOs of (a) CTF-TPN and (b) CTF-HUST-1; ESP maps of (c) CTF-TPN and (d) CTF-HUST-1; (e) proposed mechanism for the photocatalytic syngas production with $\left[\mathrm{Co}(\mathrm{bpy})_{3}\right]^{2+}$ as a catalyst under visible light irradiation. 
electrons. For CTF-HUST-1, the HOMO and LUMO are symmetrically distributed across the framework (Fig. 7b), which would increase the probability of electron and hole recombination. The electrostatic potential (ESP) results show that the triphenylamine unit in CTF-TPN exhibits more positive charges than the triazine unit, again proving that electrons flow from the triphenylamine to the triazine unit (Fig. 7c and 7d). Moreover, the negative charges on the triazine unit are beneficial for the adsorption of the cationic Co complex on the triazine units, boosting the electron transport.

Based on the above studies and DFT calculations, a reasonable mechanism for the photocatalytic reduction of $\mathrm{CO}_{2}$ by CTFs is proposed (Fig. 7e). Upon visible light irradiation, electrons are excited and transferred from the triphenylamine units to the triazine units. The holes on the triphenylamine units are captured by TEOA. The photogenerated electrons are transferred from the triazine unit to the cationic $\mathrm{Co}^{2+}$ complex, where $\left[\mathrm{Co}(\mathrm{bpy})_{3}\right]^{2+}$ is reduced to $\left[\mathrm{Co}(\mathrm{bpy})_{2}\right]^{+}$, which serves as the active site for the reduction of $\mathrm{CO}_{2}$ and $\mathrm{H}_{2} \mathrm{O}$ to $\mathrm{CO}$ and $\mathrm{H}_{2}$.

\section{Conclusions}

In summary, we have demonstrated the integration of single Co active sites within covalent triazine frameworks for the photocatalytic production of syngas via the reduction of $\mathrm{CO}_{2}$ in aqueous solution. The covalent triazine frameworks containing intramolecular heterojunctions narrow the bandgap and enhance visible light harvesting. DFT calculations revealed that the photogenerated electrons separated from the central triphenylamine units and migrated to the triazine units through intra-molecular charge-transfer, resulting in efficient carrier separation. The single Co sites in the pores of the CTFs accept electrons to reduce $\mathrm{CO}_{2}$ and $\mathrm{H}_{2} \mathrm{O}$ to syngas. Consequently, CTFs with heterojunction structures display considerable photocatalytic activity. This work not only shows the great potential of CTFs for the photocatalytic production of syngas, but also offers a deep understanding of the electron-transfer mechanism of organic semiconductor-based photocatalysis.

\section{References}

[1] Y. F. Zhao, G. I. N. Waterhouse, G. B. Chen, X. Y. Xiong, L. Z. Wu, C. H. Tung, T. R. Zhang, Chem. Soc. Rev., 2019, 48, 1972-2010.

[2] X. Li, J. Yu, M. Jaroniec, X. Chen, Chem. Rev., 2019, 119, 3962-4179.

[3] J. M. Spurgeon, B. Kumar, Energy Environ. Sci., 2018, 11, 1536-1551.

[4] M. D. Porosoff, B. H. Yan, J. G. Chen, Energy Environ. Sci., 2016, 9, 62-73.

[5] H. Wang, Y. Wang, L. Guo, X. Zhang, C. Ribeiro, T. He, Chin. J. Catal,, 2020, 41, 131-139.

[6] M. Liu, Y. F. Mu, S. Yao, S. Guo, X. W. Guo, Z. M. Zhang, T. B. Lu, Appl. Catal. B, 2019, 245, 496-501.

[7] J. C. Hu, M. X. Gui, W. Xia, J. Wu, Y. N. Zhou, N. D. Feng, J. W. Xiao, H. F. Liu, C. H. Tung, L. Z. Wu, F. Wang, J. Mater. Chem. A, 2019, 7, 10475-10482.

[8] J. S. Lee, D. I. Won, W. J. Jung, H. J. Son, C. Pac, S. O. Kang, Angew. Chem. Int. Ed., 2017, 56, 976-980.

[9] A. Li, T. Wang, X. Chang, Z. J. Zhao, C. Li, Z. Huang, P. Yang, G. Zhou, J. Gong, Chem. Sci., 2018, 9, 5334-5340.

[10] M. Liu, S. Wageh, A. A. Al-Ghamdi, P. Xia, B. Cheng, L. Zhang, J. Yu, Chem. Commun., 2019, 55, 14023-14026.

[11] X. Li, C. Liu, D. Wu, J. Li, P. Huo, H. Wang, Chin. J. Catal., 2019, 40, 928-939.

[12] J. Low, B. Dai, T. Tong, C. Jiang, J. Yu, Adv. Mater., 2019, 31, 1802981.

[13] J. Jiang, S. Cao, C. Hu, C. Chen, Chin. J. Catal., 2017, 38, 1981-1989.

[14] B. P. Biswal, H. A. Vignolo-González, T. Banerjee, L. Grunenberg, G. Savasci, K. Gottschling, J. Nuss, C. Ochsenfeld, B. V. Lotsch, J. Am. Chem. Soc., 2019, 141, 11082-11092.

[15] W. Zhong, R. Sa, L. Li, Y. He, L. Li, J. Bi, Z. Zhuang, Y. Yu, Z. Zou, J. Am. Chem. Soc., 2019, 141, 7615-7621.

[16] W. T. Eckenhoff, Coord. Chem. Rev. , 2018, 373, 295-316.

[17] J. W. Wang, W. J. Liu, D. C. Zhong, T. B. Lu, Coord. Chem. Rev., 2019, $378,237-261$.

[18] J. Xiao, W. Yang, S. Gao, C. Sun, Q. Li, J. Mater. Sci. Technol., 2018, $34,2331-2336$.

[19] C. Bie, B. Zhu, F. Xu, L. Zhang, J. Yu, Adv. Mater., 2019, 31, e1902868.

[20] D. T. Genna, A. G. Wong-Foy, A. J. Matzger, M. S. Sanford, J. Am. Chem. Soc., 2013, 135, 10586-10589.

[21] Q. Xie, W. He, S. Liu, C. Li, J. Zhang, P. K. Wong, Chin. J. Catal., 2020,

\section{Graphical Abstract}

Chin. J. Catal., 2021, 42: 123-130 doi: 10.1016/S1872-2067(20)63603-8

\section{Encapsulation of Co single sites in covalent triazine frameworks for photocatalytic production of syngas}

Yajun He, Xin Chen, Chi Huang, Liuyi Li *, Chengkai Yang, Yan Yu* Fuzhou University

Encapsulation of Co single sites in covalent triazine frameworks with intramolecular heterojunctions boosts the efficiency of photocatalytic syngas production, revealing the promising potential of covalent triazine frameworks for single-site photocatalysis.

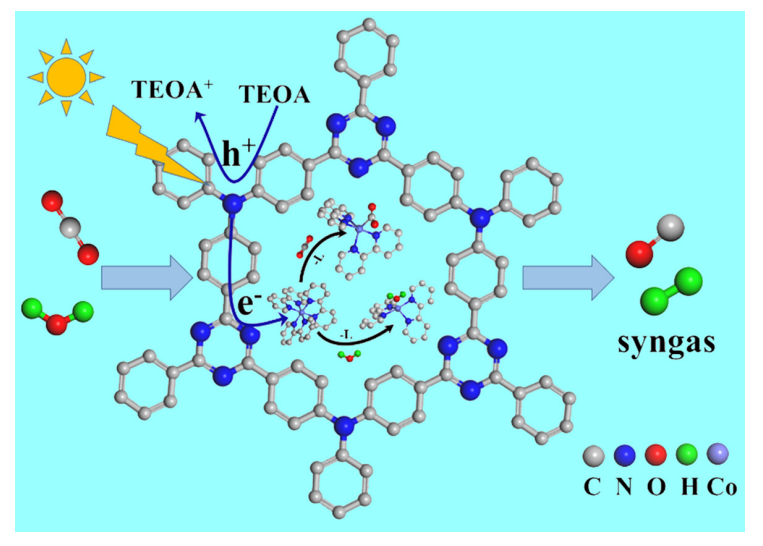


41, 140-153.

[22] W. Yu, D. Xu, T. Peng, J. Mater. Chem. A, 2015, 3, 19936-19947.

[23] D. Li, Y. Huang, S. Li, C. Wang, Y. Li, X. Zhang, Y. Liu, Chin. J. Catal., 2020, 41, 154-160.

[24] X. Liu, M. Ye, S. Zhang, G. Huang, C. Li, J. Yu, P. K. Wong, S. Liu, J. Mater. Chem. A, 2018, 6, 24245-24255.

[25] J. Bi, W. Fang, L. Li, J. Wang, S. Liang, Y. He, M. Liu, L. Wu, Macromol. Rapid Commun., 2015, 36, 1799-1805.

[26] M. Liu, Q. Huang, S. Wang, Z. Li, B. Li, S. Jin, B. Tan, Angew. Chem. Int. Ed., 2018, 57, 11968-11972.

[27] S. Kuecken, A. Acharjya, L. Zhi, M. Schwarze, R. Schomacker, A. Thomas, Chem. Commun., 2017, 53, 5854-5857.

[28] Z. A. Lan, Y. Fang, Y. Zhang, X. Wang, Angew. Chem., Int. Ed., 2018, $57,470-474$.

[29] K. Cui, W. Zhong, L. Li, Z. Zhuang, L. Li, J. Bi, Y. Yu, Small, 2019, 15, 1804419.

[30] W. Huang, B. C. Ma, H. Lu, R. Li, L. Wang, K. Landfester, K. A. I. Zhang, ACS Catal., 2017, 7, 5438-5442.

[31] H. S. Jena, C. Krishnaraj, G. Wang, K. Leus, J. Schmidt, N. Chaoui, P. Van Der Voort, Chem. Mater., 2018, 30, 4102-4111.

[32] S. Padmanaban, G. H. Gunasekar, M. Lee, S. Yoon, ACS Sustain. Chem. Eng., 2019, 7, 8893-8899.

[33] Y. Ren, D. Zeng, W. J. Ong, Chin. J. Catal., 2019, 40, 289-319.
[34] H. Zhong, Z. Hong, C. Yang, L. Li, Y. Xu, X. Wang, R. Wang, ChemSusChem, 2019, 12, 4493-4499.

[35] S. Hug, M. E. Tauchert, S. Li, U. E. Pachmayr, B. V. Lotsch, J. Mater. Chem., 2012, 22, 13956-13964.

[36] H. Zhong, C. Yang, L. Li, Y. Xu, X. Wang, R. Wang, ChemSusChem, 2019, 12,4493-4499.

[37] Q. Wang, W. Wang, L. Zhang, Y. Su, K. Wang, H. Wu, J. Mater. Sci. Technol., 2018, 34, 2337-2341.

[38] M. Liu, Q. Huang, S. Wang, Z. Li, B. Li, S. Jin, B. Tan, Angew. Chem. Int. Ed., 2018, 57, 11968-11972.

[39] Z. Zhou, W. Zhong, K. Cui, Z. Zhuang, L. Li, L. Li, J. Bi, Y. Yu, Chem. Commun., 2018, 54, 9977-9980.

[40] K. Wang, L. Yang, X. Wang, L. Guo, G. Cheng, C. Zhang, S. Jin, B. Tan, A. Cooper, Angew. Chem. Int. Ed., 2017, 56, 14149-14153.

[41] J. Low, B. Cheng, J. Yu, Appl. Surf. Sci., 2017, 392, 658-686.

[42] Y. Xia, Z. Tian, T. Heil, A. Meng, B. Cheng, S. Cao, J. Yu, M. Antonietti, Joule, 2019, 3, 2792-2805.

[43] E. X. Han, Y. Y. Li, Q. H. Wang, W. Q. Huang, L. Luo, W. Hu, G. F. Huang, J. Mater. Sci. Technol., 2019, 35, 2288-2296.

[44] J. Low, J. Yu, M. Jaroniec, S. Wageh, A. A. Al-Ghamdi, Adv. Mater., 2017, 29, 1601694.

[45] Y. Xu, Y. Ye, T. Liu, X. Wang, B. Zhang, M. Wang, H. Han, C. Li, J. Am. Chem. Soc, 2016, 138, 10726-10729.

\section{共价三嗪框架复合Co单活性位点光催化制合成气}

何亚军, 陈 金金, 黄 驰, 李留义 ${ }^{*}$, 杨程凯, 于 岩\#

福州大学材料科学与工程学院, 生态材料先进技术重点实验室, 福建福州 350108

摘要: 合成气是费托合成的关键原料, 目前其主要是通过天然气重整或煤气化来制备, 但是该制备过程需要苛刻的合成条 件. 光催化技术利用太阳能将 $\mathrm{CO}_{2}$ 还原制备合成气是未来能源开发的重要研究方向. 到目前为止, 已经开发了许多用于生 产合成气的光催化系统. 然而, 大多数催化体系使用昂贵的金属如Re和 Ru作为光敏剂和或催化剂, 利用非贵金属催化剂光 催化还原 $\mathrm{CO}_{2}$ 制合成气是实现环境可持续发展的一种有效方法. 共价三嗪框架(CTF)由于具有可调节的光吸收性质、在分 子水平上可调节的电子结构、高表面积和富氮结构, 因而在光催化体系中具有明显优势. 在此, 我们设计了一种基于分子 内异质结的CTF光催化 $\mathrm{CO}_{2}$ 还原生成合成气体系, 通过傅里叶变换红外光谱(FT-IR)、核磁共振波谱(NMR)和X射线光电子 能谱(XPS)等表征证明了CTF内的分子内异质结, 采用X射线多晶衍射(XRD)、比表面积及孔隙度分析(BET)、扫描电子显 微镜(SEM)、透射电子显微镜(TEM)和紫外-可见吸收光谱(UV-Vis DRS)等表征手段充分研究了CTF的组成、结构与光学性 质. 将所制备的 CTF光催化剂应用于可见光催化还原 $\mathrm{CO}_{2}$ 反应中, 实验结果表明, 基于分子内异质结的 CTF在 $10 \mathrm{~h}$ 内达到 $3303 \mu \mathrm{mol} \mathrm{g} \mathrm{g}^{-1}\left(\mathrm{CO}: \mathrm{H}_{2}=1.4: 1\right)$ 的合成气产率, 相对于不具有分子内异质结的CTF催化体系, 产率提高了3倍. 时间分辨苂光 发射衰减光谱、荧光光谱和瞬时光电流图谱等测试结果表明, 分子内异质结极大提高了 CTF内光生载流子的空间分离和转 移效率. 反应体系中自组装形成的吡啶 $\mathrm{Co}$ 配合物作为 $\mathrm{Co}$ 单活性位点可有效吸附和配位活化 $\mathrm{CO}_{2}$ 分子. 理论计算进一步证 明含有分子内异质结结构的 CTF能极大地促进电荷分离效率, 从而实现催化性能的增强. 这项工作不仅显示了 CTF在光催 化等领域潜在的应用前景, 而且为合理设计基于CTF的光催化体系提供了新的见解.

关键词: 合成气; 光催化; 共价三嗪框架; 二氧化碳还原; 单点催化剂; 合成气

收稿日期: 2020-02-26. 接受日期: 2020-04-10. 出版日期: 2021-01-05.

*通讯联系人. 电子信箱: lyli@fzu.edu.cn

\#通讯联系人. 电子信箱: yuyan@fzu.edu.cn

基金来源：国家自然科学基金(U1905215, 51672046); 福建省自然科学基金(2019J01226); 能源与环境光催化国家重点实验室开 放课题(SKLPEE-KF201815).

本文的电子版全文由Elsevier出版社在ScienceDirect上出版(http://www.sciencedirect.com/science/journal/18722067). 